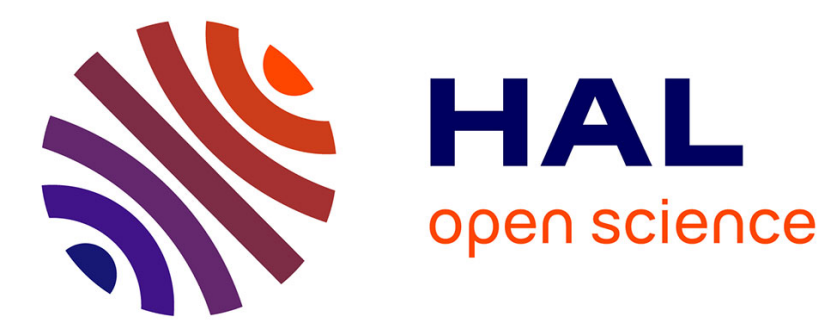

\title{
Preparation of core-shell silver/silica nanoparticles and their application for enhancement of cyanine 3 fluorescence
}

N. Sui, Virginie Monnier, Z. Yang, Y. Chevolot, Emmanuelle Laurenceau, E. Souteyrand, V. Dugas

\section{To cite this version:}

N. Sui, Virginie Monnier, Z. Yang, Y. Chevolot, Emmanuelle Laurenceau, et al.. Preparation of core-shell silver/silica nanoparticles and their application for enhancement of cyanine 3 fluorescence. International Journal of Nanoscience, 2012, 11 (04), 10.1142/S0219581X12400200 . hal-01846303

\section{HAL Id: hal-01846303 https://hal.science/hal-01846303}

Submitted on 23 Jul 2018

HAL is a multi-disciplinary open access archive for the deposit and dissemination of scientific research documents, whether they are published or not. The documents may come from teaching and research institutions in France or abroad, or from public or private research centers.
L'archive ouverte pluridisciplinaire HAL, est destinée au dépôt et à la diffusion de documents scientifiques de niveau recherche, publiés ou non, émanant des établissements d'enseignement et de recherche français ou étrangers, des laboratoires publics ou privés. 


\title{
PREPARATION OF CORE-SHELL SILVER/SILICA NANOPATICLES AND THEIR APPLICATION FOR ENHANCEMENT OF CYANINE 3 FLUORESCENCE
}

\author{
N. SUI*, V. MONNIER ${ }^{\dagger}$, Z. YANG, Y. CHEVOLOT, E. LAURENCEAU \\ and E. SOUTEYRAND \\ Université de Lyon, Institut des Nanotechnologies de Lyon \\ INL UMR 5270 Site Ecole Centrale de Lyon \\ 36 Avenue Guy de Collongue, 69134 Ecully, Cedex, France \\ *ning.sui@ec-lyon.fr \\ †virginie.monnier@ec-lyon.fr \\ V. DUGAS \\ Université de Lyon, Université Claude Bernard Lyon 1, Laboratoire \\ des Sciences Analytiques UMR 5180 \\ 43 bd du 11 Novembre 1918, 69622 Villeurbanne Cedex, France
}

Received 28 November 2011

Accepted 2 May 2012

Published 7 September 2012

\begin{abstract}
Core shell $\mathrm{Ag} @ \mathrm{SiO}_{2}$-Streptavidin-Cy3 nanoparticles were prepared. $\mathrm{Ag} @ \mathrm{SiO}_{2}$ nanoparticles were synthesized via a sol-gel method. Then, Streptavidin-Cy3 was covalently bonded to the $\mathrm{Ag} @ \mathrm{SiO}_{2}$ surface. These core-shell nanoparticles were characterized by steady-state fluorescence spectroscopy and fluorescence scanning. In presence of the silver core, a 2.5-time enhancement of Cy3 fluorescence intensity was obtained. This result shows that these nanoparticles can be potentially helpful in surface analysis based on biochip.
\end{abstract}

Keywords: $\mathrm{Ag} @ \mathrm{SiO}_{2}$; surface enhancement; fluorescence.

\section{Introduction}

Surface-Enhanced fluorescence (SEF) has provoked much attention for the recent years. SEF appears when a metal is located close to a fluorophore. Indeed, localized surface plasmon resonance (LSPR) can be created via direct illumination of a metal nanostructure. Consequently, sharp spectral absorption and scattering peaks as well as strong electromagnetic near-field can be observed. These properties can affect strongly the fluorescence emission of the fluorophore. The interaction between near-field of metal nanostructure and fluorophore can be controlled by metal-fluorophore distance, excitation wavelength, and coupling between plasmonic modes and fluorophores. ${ }^{1-3}$ LSPR of silver and gold show strong SEF effects on organic and inorganic fluorophores. ${ }^{1,3}$ Different kinds of nanostructures have been investigated, including nanoparticles, islands, nanoshells, nanorods. The interesting optical properties of these nanostructures have greatly extended the application of SEF, and have found potential applications in the field of cell 
imaging, ${ }^{4}$ photoinduced oxidation, ${ }^{5}$ DNA and RNA detection, ${ }^{6}$ label-free bioassays. ${ }^{7}$

Organic fluorophores (like fluorescein, cyanines, rhodamine) are widely used to label target biomolecules in biological assays. They exhibit many advantages such as a narrow fluorescence emission peak, a high fluorescence intensity, and an easy bioconjugation to biomolecules. Among them, Cyanine 3 (Cy3) is one of the most used. However, its quantum yield is only $4 \%,{ }^{8}$ thus, high concentrations of $\mathrm{Cy} 3$ must be used in order to obtain efficient labeling.

Recent research reveals that the fluorophore intrinsic quantum yield plays a significant role in SEF. Indeed, the highest enhancement is obtained for low quantum yield fluorophores. ${ }^{9}$ In this case, it has been shown that the expected enhancement can be as large as the inverse of the intrinsic quantum yield. ${ }^{10}$

In this work, we fabricated $\mathrm{Ag} @ \mathrm{SiO}_{2}$ core-shell nanoparticles in order to enhance the fluorescence signal of Cy3. These nanoparticles are composed of a $60 \mathrm{~nm}$-diameter silver core, coated with a $20 \mathrm{~nm}$ thick silica layer as an optically transparent spacer between silver and Cy3. $60 \mathrm{~nm}$-silver colloids were chosen as core metal because their plasmon band matches well the absorption band of Cy3. A combination of a $60 \mathrm{~nm}$ metal core and a spacer thickness of $20 \mathrm{~nm}$ was selected considering previous studies. ${ }^{3,4}$ In these conditions, the electric field intensity is sufficiently intense at a distance of $20 \mathrm{~nm}$ to the core surface to obtain both a fluorescence enhancement effect on $\mathrm{Cy} 3$ and to avoid quenching. Cy3 labeled with Streptavidin was covalently bonded onto the surface of $\mathrm{Ag} @ \mathrm{SiO}_{2}$. The structural properties of $\mathrm{Ag} @ \mathrm{SiO}_{2}$ and the SEF effect with $\mathrm{Cy} 3$ were investigated in detail. At last, fluorescence properties of these samples were determined under steady-state fluorescence spectroscopy and fluorescence scanning.

\section{Experimental Section}

\subsection{Chemicals}

Tetraethyl orthosilicate (TEOS), 3-aminopropyltri methoxysilane (APTMS), 3-aminopropyltriethoxysilane (APTES), sodium silicate solution $\left(\mathrm{Na}_{2} \mathrm{O}\left(\mathrm{SiO}_{2}\right)_{3-5}, 27\right.$ wt. $\left.\% \mathrm{SiO}_{2}\right)$, ammonia solution $(25 \%-28 \%)$, isopropanol and polyvinylpyrrolidone with average molecular weight of $10000 \mathrm{~g} / \mathrm{mol}$ (PVP10) were purchased from Sigma-Aldrich. 3-aminopropyldimethylethoxysilane (APDES) was obtained from ABCR. Silver colloids (diameter: $60 \mathrm{~nm}$ ) were obtained from British BioCell International. Streptavidin-Cy3 Conjugate was obtained from Jackson ImmunoResearch. Coomassie Brilliant Blue G (CBB) was provided by SigmaAldrich. 0.01 M PBS ( $\mathrm{pH} 7.4$ ) was prepared by dissolving the content of one pouch of dried powder in $1 \mathrm{~L}$ of ultrapure water. Milli-Q water $(18.2 \mathrm{M} \Omega$ ) was used in all the preparations.

\subsection{Synthesis of $\mathrm{Ag} @ \mathrm{SiO}_{2}$ particles}

The synthesis of $\mathrm{Ag} @ \mathrm{SiO}_{2}$ particles was achieved following a reported procedure with some modifications (Scheme 1). ${ }^{11}$ In a typical synthesis, $2 \mathrm{~mL}$ of $\mathrm{Ag}$ colloids $\left(2.6 \times 10^{10}\right.$ particles $\left./ \mathrm{mL}\right)$ were mixed with $50 \mu \mathrm{L}$ of PVP10 solution $(12.8 \mathrm{~g} / \mathrm{L})$, the reaction mixture was stirred for $24 \mathrm{~h}$ at room temperature. The PVP modified Ag colloids were collected by centrifugation and re-dispersed in $14.4 \mu \mathrm{L}$ of water, $160 \mu \mathrm{L}$ of 2 -propanol and $8 \mu \mathrm{L}$ of ammonia. After stirring for $10 \mathrm{~min}, 0.5 \mu \mathrm{L}$ of TEOS solution (10 vol.\% in ethanol) was added. The reaction mixture was then stirred for another $1 \mathrm{~h}$. The product was separated by centrifugation at $10000 \mathrm{rpm}$ for $10 \mathrm{~min}$, and finally dispersed in $2 \mathrm{~mL}$ of ethanol.
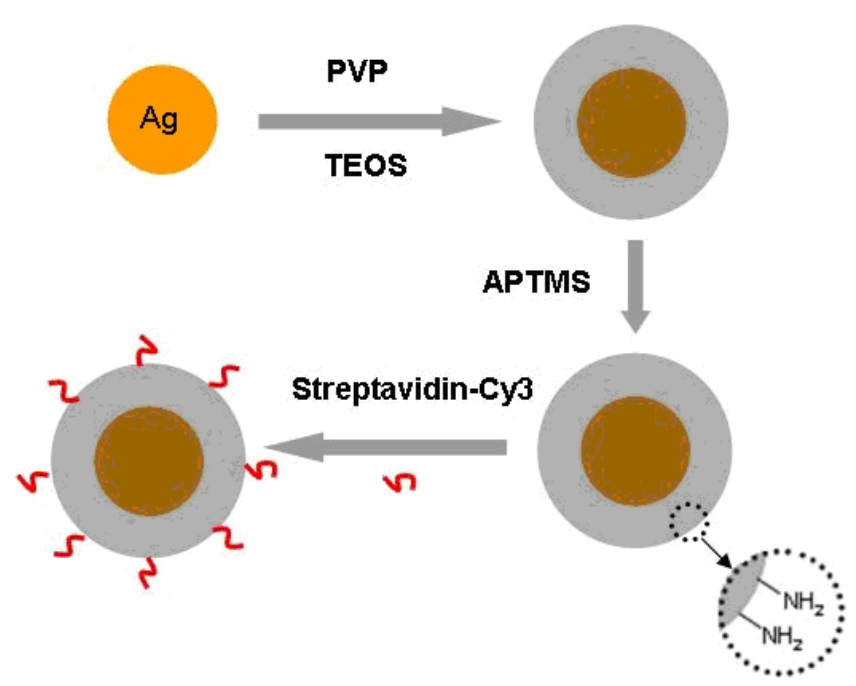

Scheme 1. Schematic illustration of synthesis process of coreshell $\mathrm{Ag} @ \mathrm{SiO}_{2}$ nanoparticles and covalent bonding of Streptavidin-Cy3 to the surface. 


\subsection{Surface functionalization of $\mathrm{Ag} @ \mathrm{SiO}_{2}$ nanoparticles with amino groups}

$\mathrm{Ag} @ \mathrm{SiO}_{2}$ nanoparticles were functionalized with APTMS, APTES or APDES using a reported method. ${ }^{12}$ The amount of APTMS was calculated to be sufficient to provide approximately a 5 -monolayer coating on silica particles. $50 \mu \mathrm{L}$ of aminosilane solution in ethanol $(1 \mathrm{mM})$ was added into $1 \mathrm{~mL}$ of $\mathrm{Ag} @ \mathrm{SiO}_{2}$ dispersion. After stirring overnight, the solution was refluxed at $80^{\circ} \mathrm{C}$ for two additional hours. The amino-functionalized $\mathrm{Ag} @ \mathrm{SiO}_{2}$ particles were purified with several centrifugation-washing steps in ethanol. The surface density of amino groups was determined by CBB titration, using a previously reported method. ${ }^{13}$

\subsection{Conjugation of NHS-ester Streptavidin-Cy3 to $\mathrm{Ag} @ \mathrm{SiO}_{2}$ particles}

$200 \mu \mathrm{L}$ as-prepared $\mathrm{Ag} @ \mathrm{SiO}_{2}-\mathrm{NH}_{2}$ nanoparticles were dispersed in a PBS solution. Then $5 \mu \mathrm{L}$ of $N$-hydroxysuccinimide (NHS) ester of StreptavidinCy3 $(0.01 \mathrm{mg} / \mathrm{mL})$ was added and the mixture was allowed to react overnight at $4^{\circ} \mathrm{C}$.

\subsection{Preparation of reference samples}

Silica nanoparticles were selected as reference for fluorescence enhancement measurement. They were prepared using a variation of the method developed by Stöber et al. ${ }^{14} \mathrm{~A}$ solution of $3 \mathrm{~mL}$ of ammonia was mixed with $50 \mathrm{~mL}$ of dry ethanol. Then $1.5 \mathrm{~mL}$ of TEOS was added and the solution was stirred overnight. With this method, silica nanoparticles exhibiting a diameter of approximately $100 \mathrm{~nm}$ were obtained. The surface amino functionalization and conjugation of Streptavidin-Cy3 were the same as the ones used for $\mathrm{Ag} @ \mathrm{SiO}_{2}$ nanoparticles.

\subsection{Characterization methods}

SEM images were obtained with an Inspect S50 microscope from FEI working at $10 \mathrm{kV}$. For SEM, samples were prepared by drop-casting $2 \mu \mathrm{L}$ of the $\mathrm{Ag} @ \mathrm{SiO}_{2}$ nanoparticles dispersion on a silicon wafer substrate. ImageJ $1.40 \mathrm{~g}$ software was used for image analysis. UV-Visible absorption spectra were obtained on a SAFAS UV mc2 double-beam spectrophotometer using a micro-cuve of $1 \mathrm{~mm}$ length containing $5 \mu \mathrm{L}$ of solution to analyze. Infrared spectra were done in ATR mode with a Nicolet 6700 spectrometer from Thermo Scientific. Fluorescence steady-state spectroscopy was achieved with a SPEX $16810.22 \mathrm{~m}$ fluorimeter (excitation: $532 \mathrm{~nm}$, detection: $560-700 \mathrm{~nm})$. For fluorescence scanning experiments, $20 \mu \mathrm{L}$ of nanoparticles solutions were drop-casted on nonfluorescent glass slides (Schott Nexterion®) Glass D). Glass slides were scanned with a GenePix 4100 A microarray scanner (Axon Instruments) at excitation wavelength of $532 \mathrm{~nm}$ and detection wavelength of $575 \mathrm{~nm}$ for the Cy3 dyes. Images were analyzed with GenePix Pro 6.0 software.

\section{Results and Discussion}

\subsection{Core-shell Ag@SiO nanoparticles}

Sol-gel silica coating of noble-metal colloids is a common method used in different situations for several reasons: (i) the optical properties of metal colloids can be tailored by its dielectric constant, ${ }^{15}$ (ii) silica is a chemically inert material that can prevent aggregation, (iii) the thickness of silica coating can be controlled at the nanometer-scale by the sol-gel synthesis, (iv) silica is well adapted for further conjugations of biomolecules or fluorophores. ${ }^{16}$ However, a main problem when manipulating metal colloids is that their surface stabilizer is very sensitive to their dispersion medium, which can induce coalescence. Several indirect silica coating methods have been developed: for instance, LizMarzan used an aminosilane to functionalize gold colloids, then sodium silicate was added to form a thin silica shell, and finally, modified colloids can be easily transferred into an alcohol-water mixture. ${ }^{17}$ Graf et al. used PVP as a coupling agent to functionalize metal colloids. This amphiphilic nonionic polymer is soluble in water and in many nonaqueous solvents. Thus, it can be adsorbed onto many different surfaces. ${ }^{11}$ This method is quite general and can be employed for different kinds of metal colloids, such as gold or silver. Herein, we employed Graf's method to elaborate the core-shell $\mathrm{Ag} @ \mathrm{SiO}_{2}$ nanoparticles. The commercial silver colloids are initially functionalized with sodium citrate and dispersed in water, thus they bear negative charges. PVP can be adsorbed on their surface after $24 \mathrm{~h}$ of 


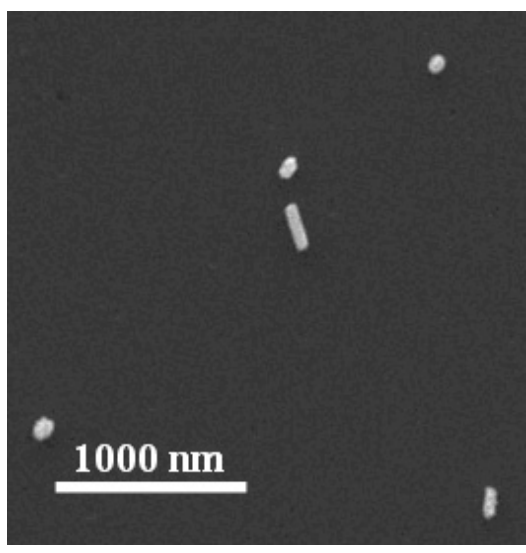

(a)

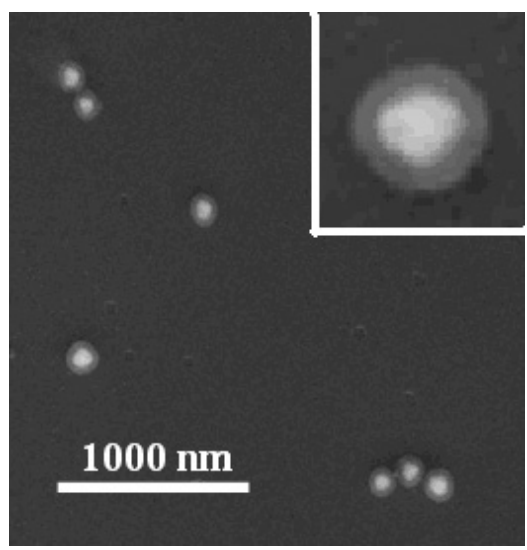

(b)

Fig. 1. Ag colloids (a) and core-shell $\mathrm{Ag} @ \mathrm{SiO}_{2}$ nanoparticles (b).

reaction at room temperature. Then, the nanoparticles are transferred into 2-propanol, water, ammonia mixture and TEOS as source of silica. The reaction is kept for $2 \mathrm{~h}$ at $40^{\circ} \mathrm{C}$.

SEM images of commercial Ag colloids and asprepared core-shell $\mathrm{Ag} @ \mathrm{SiO}_{2}$ nanoparticles are shown in Fig 1. The size distribution of commercial $\mathrm{Ag}$ colloids is broad, the diameter varies from 60 to $90 \mathrm{~nm}$, and also some nanorods are visible. Different sizes or shapes of metal colloids lead to different plasmon oscillation frequencies. ${ }^{18}$ Thus, the plasmon band of these commercial Ag colloids is broad and located between $350 \mathrm{~nm}$ and $600 \mathrm{~nm}$, as shown by UV-vis absorption (Fig. 2). After silica layer coating, a homogenous shell of $20 \mathrm{~nm}$ of thickness

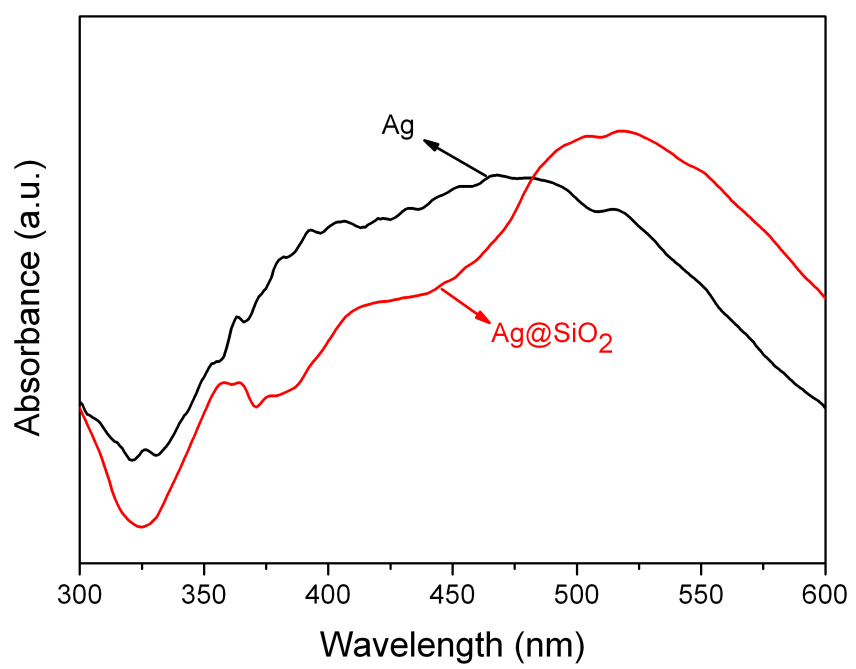

Fig. 2. UV-Visible absorption spectra of Ag colloids and coreshell $\mathrm{Ag} @ \mathrm{SiO}_{2}$ nanoparticles. has been achieved. Consequently, the plasmon band red shifted, due to the increase of the local refractive index around the Ag colloids. ${ }^{19}$

\subsection{Conjugation of Streptavidin-Cy3 to $\mathrm{Ag} @ \mathrm{SiO}_{2}$ nanoparticles}

$\mathrm{Ag} @ \mathrm{SiO}_{2}$ nanoparticles were firstly amino functionalized. Three aminosilane molecules were selected, as shown in Table 1. The density of amino groups on the silica surface was evaluated by colorimetric titration with CBB. ${ }^{13}$ From Table 1, we can see that with APTMS and APTES almost the same density of amino groups is obtained on silica surface, while with APDES, the density is weaker. Indeed, APTMS has three very reactive alkoxy functions, APTES has three less reactive alkoxy functions and APDES has only one weakly reactive function.

In the process of immobilization, after the alkoxy hydrolysis, the siloxane function reacts with hydroxyl groups on the silica surface, thus more reactive functions the molecule owns, more immobilization capability it has. Thus, APTMS and APTES are easier to immobilize onto silica surface than APDES. In the following, we used APTMS for the high density of amino groups it provides.

Finally, Streptavidin-Cy3 was conjugated to the amino groups. A schematic representation of Streptavidin-Cy3 conjugation to amino-modified $\mathrm{Ag} @ \mathrm{SiO}_{2}$ with APTMS is presented in Scheme 2. Streptavidin-Cy3 includes an activated ester function which can react with amino group to form an amide covalent bond. ${ }^{20}$ The conjugation of Streptavidin-Cy3 should be performed in $\mathrm{PBS}$ at $4{ }^{\circ} \mathrm{C}$ 
Table 1. Aminosilane molecules chemical formula and amino density immobilized on silica surface.

APTMS (3-aminopropyltrimethoxysilane)

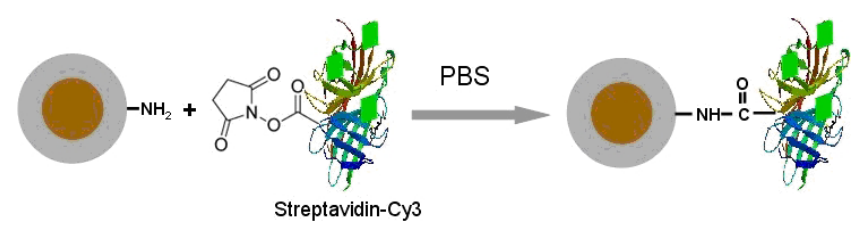

Scheme 2. Schematic illustration Streptavidin-Cy3 conjugation to $\mathrm{Ag} @ \mathrm{SiO}_{2}$ nanoparticle.

under stirring because higher temperature will induce the loss of activity of activated ester function. A controlled amount of Streptavidin-Cy3 molecule was added, equal to the total amount of amino groups onto silica surface.

\section{Metal-Enhanced Fluorescence Intensity}

To prove that the fluorescence enhancement is due to the presence of metal core, a reference consisting in pure silica nanoparticles conjugated with the same amount of Streptavidin-Cy3, was prepared. Figure 3 shows the fluorescence emission intensity of $\mathrm{Ag} @ \mathrm{SiO}_{2}-\mathrm{Streptavidin-Cy3}$ nanoparticles compared to the $\mathrm{SiO}_{2}$-Streptavidin-Cy3 reference. The emission intensity of $\mathrm{Ag} @ \mathrm{SiO}_{2}$-Streptavidin-Cy3 was approximately 2.5 times higher than the reference sample.

Lakowicz proposed that the fluorescence enhancement is due to the increase of fluorophore quantum yield. ${ }^{9}$ The intrinsic quantum yield $\left(\mathcal{Q}_{0}\right)$ of fluorophore is given by:

$$
\mathcal{Q}_{0}=\frac{\Gamma}{\Gamma+k_{n r}}
$$

Here, $\Gamma$ and $k_{n r}$ represent respectively radiative decay rate and nonradiative decay rate. In the presence of a metal, the radiative decay rate near the metal is increased and is given by $\Gamma+\Gamma_{m}, \Gamma_{m}$ is the additional radiative decay rate due to the metal, the quantum yield $\mathcal{Q}_{m}$ of fluorophores near the metal thus become:

$$
\mathcal{Q}_{m}=\frac{\Gamma+\Gamma_{m}}{\Gamma+\Gamma_{m}+k_{n r}}
$$

The metal-induced change to $\Gamma+\Gamma_{m}$ results in an increase of the quantum yield, due to an increase of the weight of the radiative processes compared to the nonradiative processes. Thus, the quantum yield enhancement $\left(\mathcal{Q}_{m} / \mathcal{Q}_{0}\right.$ ratio $)$ is more efficient for fluorophores exhibiting a low intrinsic quantum yield $\mathcal{Q}_{0}$.

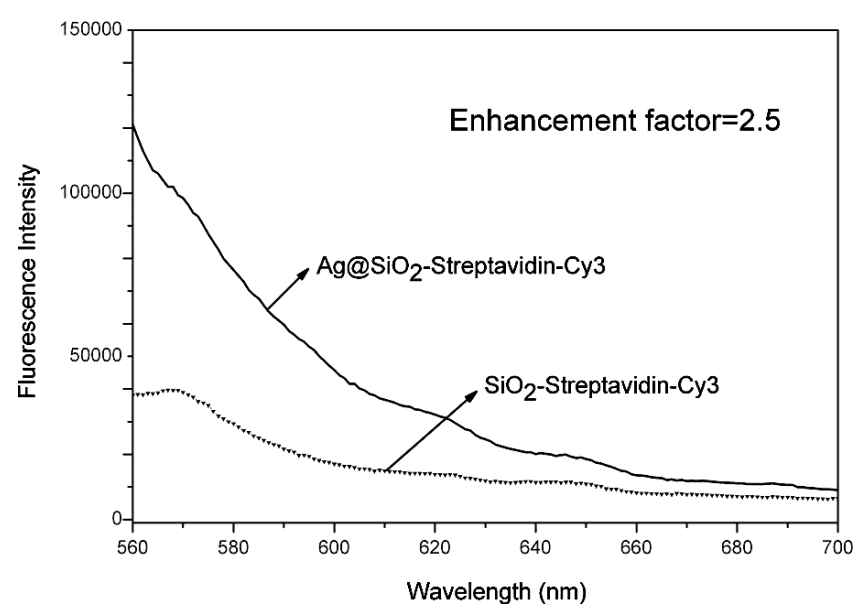

Fig. 3. Fluorescence emission spectra of $\mathrm{Ag} @ \mathrm{SiO}_{2}$-Streptavidin-Cy3 nanoparticles (black) and reference sample (red). 


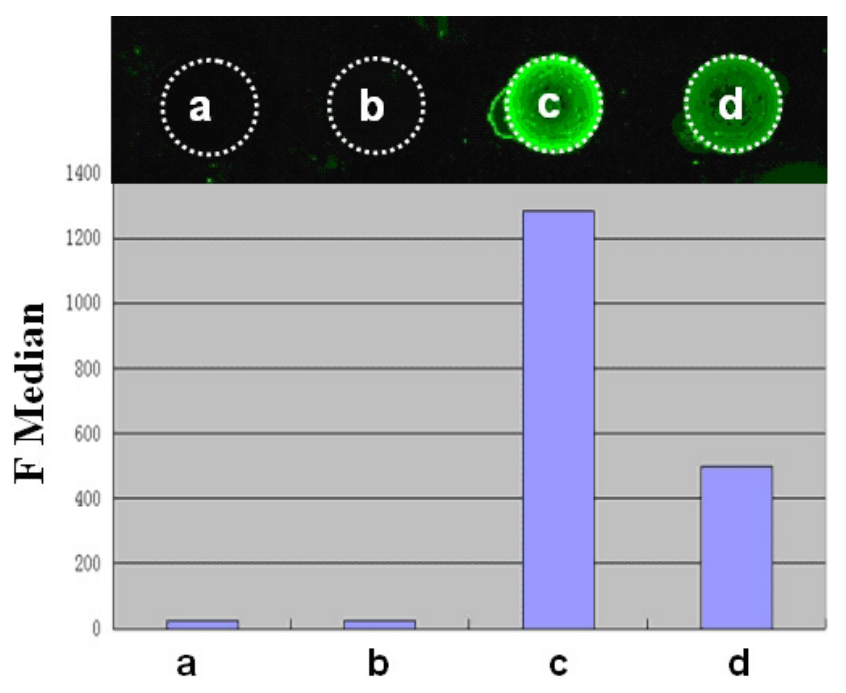

Fig. 4. Fluorescence image and median value of fluorescence intensity (F Median) for (a) only glass slide, (b) $\mathrm{Ag} @ \mathrm{SiO} 2$, (c) $\mathrm{Ag} @ \mathrm{SiO}_{2}-$ Streptavidin-Cy3, and (d) $\mathrm{SiO}_{2}$-Streptavidin-Cy3.

Finally, the fluorescence properties of $\mathrm{Ag} @ \mathrm{SiO}_{2}$ Streptavidin-Cy3 nanoparticles were evaluated on a glass slide in order to test them in "real" bioassay conditions. Different samples were dropped on glass slides (Fig. 4) and their fluorescence intensities were compared on a fluorescence scanner, in the excitation and emission conditions generally used for Cy3. We can see that there is no fluorescence intensity for the blank consisting of only glass slide [Fig. 4(a)] and $\mathrm{Ag} @ \mathrm{SiO}_{2}$ nanoparticles [Fig. 4(b)]. The fluorescence intensity of $\mathrm{Ag} @ \mathrm{SiO}_{2}$-Streptavidin-Cy3 is brighter than $\mathrm{SiO}_{2}$-Streptavidin-Cy3 The calculations show that the median fluorescence value is increased by 2.6 -times. Thus, these silicacoated metal-fluorescent nanoparticles are an effective way to obtain a fluorescence enhancement, and will probably find their application potential in biochips.

\section{Conclusion}

In conclusion, we have synthesized $\mathrm{Ag} @ \mathrm{SiO}_{2}$ nanoparticles, which can be conjugated to Streptavidin$\mathrm{Cy} 3$ molecules after silica surface modification. The fluorescence properties of $\mathrm{Ag} @ \mathrm{SiO}_{2}$-Streptavidin$\mathrm{Cy} 3$ nanoparticles were determined under steadystate fluorescence spectroscopy and fluorescence scanning. A 2.5-time enhancement of fluorescence was achieved. Further work will be to optimize different parameters such as the nature and shape of the metal core, the metal-fluororophore distance to improve the fluorescence enhancement.

\section{References}

1. O. Kulakovich, N. Strekal, A. Yaroshevich, S. Maskevich, S. Gaponenko, I. Nabiev, U. Woggon and M. Artemyev, Nano Lett. 2, 1449 (2002).

2. M. M. Maye, O. Gang and M. Cotlet, Chem. Commun. 46, 6111 (2010).

3. O. G. Tovmachenko, C. Graf, D. J. V. D. Heuvel, A. V. Blaaderen and H. C. Gerritsen, Adv. Mater. 18, 91 (2006).

4. F. Zhang, G. B. Braun, Y. Shi, Y. Zhang, X. Sun, N. O. Reich, D. Zhao and G. Stucky, J. Am. Chem. Soc. 132, 2850 (2010).

5. K. Mori, M. Kawashima, M. Che and H. Yamashita, Angew. Chem. Int. Ed. 49, 8598 (2010).

6. Y. Wang, B. Liu, A. Mikhailovsky and G. C. Bazan, Adv. Mater. 22, 656 (2010).

7. K. Ray, H. Szmacinski and J. R. Lakowicz, Anal. Chem. 81, 6049 (2009).

8. R. B. Mujumdar, L. A. Ernst, S. R. Mujumdar, C. J. Lewis and A. S. Waggoner, Bioconjug. Chem. 4, 105 (1993).

9. J. R. Lakowicz, Anal. Biochem. 298, 1 (2001).

10. J. Kim, G. Dantelle, A. Revaux, M. Berard, A. Huignard, T. Gacoin and J. P. Boilot, Langmuir 26, 8842 (2010).

11. C. Graf, D. L. J. Vossen, A. Imhof and A. V. Blaaderen, Langmuir 19, 6693 (2003).

12. S. L. Westcott, S. J. Oldenburg, T. R. Lee and N. J. Halas, Langmuir 14, 5396 (1998).

13. G. Coussot, E. Nicol, A. Commeyras, I. Desvignes, R. Pascal and O. Vandenabeele-Trambouze, Polym. Int. 58, 511 (2009).

14. W. Stöber, A. Fink and E. Bohn, J. Colloid Interface Sci. 26, 62 (1968). 
15. J. Rodriguez-Fernandez, I. Pastoriza-Santos, J. Perez-Juste, F. J. G. D. Abajo and L. M. LizMarzan, J. Phys. Chem. C 111, 13361 (2007).

16. S. H. Liu, Z. H. Zhang and M. Y. Han, Anal. Chem. 77, 2595 (2005).

17. L. M. Liz-Marzan, M. Giersig and P. Mulvaney, Langmuir 12, 4329 (1996).
18. K. M. Mayer and J. F. Hafner, Chem. Rev. 111, 3828 (2011).

19. K. Aslan, M. Wu, J. R. Lakowicz and C. D. Geddes, J. Am. Chem. Soc. 129, 1524 (2007).

20. V. Dugas, G. Depret, Y. Chevalier, X. Nesme and E. Souteyrand, Sens. Actuators B-Chem. 101, 112 (2004). 